\title{
EL MERCADO DE PINTURA ESPAÑOLA EN ESTADOS UNIDOS EN LAS PRIMERAS DÉCADAS DEL SIGLO XIX
}

Guadalupe Carrasco-González

Universidad de Cádiz

Data recepción: 2018/04/19

Data aceptación: 2019/05/11

Contacto autora: guadalupe.carrasco@uca.es

ORCID: https://orcid.org/0000-0002-5843-5811

\section{RESUMEN}

En Estados Unidos el fenómeno del coleccionismo se desarrolló a partir de la segunda mitad del siglo XIX. Fueron escasas las colecciones artísticas en las primeras décadas del siglo. En este artículo se analiza la llegada al mercado de arte estadounidense de la importante colección de Richard W. Meade, reunida durante su estancia en España entre 1804 y 1820. Buena parte de las pinturas que la componían eran de artistas barrocos españoles. A través del inventario de su patrimonio y los catálogos de las sucesivas subastas se analiza, cómo se reunió la colección y cómo contribuyó en esos años a iniciar el mercado estadounidense de pintura europea y española en particular.

Palabras clave: Estados Unidos, Richard W. Meade, Murillo, Cádiz, Barroco

\section{ABSTRACT}

In the United States, the phenomenon of art collecting grew in the second half of the 19th century, collections having been relatively small in number in the early decades of the century. This article analyses the arrival of Richard W. Meade's sizeable collection in the American art market, one that he amassed during his time in Spain between 1804 and 1820. Many of the paintings it contains were the work of Spanish baroque artists. In taking an inventory of its heritage and looking at the catalogues of various auctions, an analysis is offered of the means by which the collection came together and the contribution it made it in launching the American market for European and Spanish art in particular.

Keywords: United States, Richard W. Meade, Murillo, Cádiz, Baroque

\section{Introducción}

El coleccionismo de obras de arte fue una manifestación cultural que se desarrolló en España durante los siglos XVII y XVIII y que en este último siglo se llega a convertir en un medio de promoción y distinción social y cultural. Se trata de una actividad ligada casi de manera exclusiva a las clases privilegiadas (nobleza y clero), aunque también tiene cabida entre la burguesía, particularmente entre los mercaderes y hombres de negocios que mantenían relaciones comercia- les con América y Europa y entre los letrados y funcionarios. Ciertamente, en Sevilla y Cádiz el comercio con América favoreció la formación de grandes fortunas, buena parte de las cuales se invirtieron en bienes raíces, en el lujoso mobiliario de sus viviendas y en bibliotecas y colecciones de arte. Son bastante bien conocidos las colecciones artísticas sevillanas, especialmente las de las casas nobiliarias, las de algunos comerciantes y también las de miembros del clero'. En Cádiz la inclinación al coleccionismo se reflejó, en la segunda mitad del siglo XVIII, en las colecciones de 
algunos señalados comerciantes como Guillermo Terry, marqués de la Cañada², Sebastián Martínez Pérez, Pedro Alonso O'Crowley, el Conde de Maule, Juan Nicolás Böhl de Faber y Bernardo de Elías, sobre los que existen profundos análisis³. Pero no solo se trataba de reunir obras de arte, sino de dar a conocer la existencia misma de las colecciones, de manera que los viajeros que de manera frecuente arribaban a Cádiz recogían en sus memorias referencias sobre sus propietarios y la calidad y composición de la colección. Antonio Ponz ${ }^{4}$ constata en 1791, el interés de algunas "personas de buen gusto... por las colecciones de pinturas y otras curiosidades muy estimables". El propio Ponz visitó algunas de las casas de Cádiz donde había destacadas colecciones, citando, entre otras, la de Sebastián Martínez formada por al menos 300 pinturas. Otro viajero, el estadounidense Mordecai Noah que pasó por Cádiz entre 1813 también aprecia el interés por las bellas artes que se percibe en la ciudad señalando, con admiración, la presencia de una Academia de Dibujo y Bellas Artes y la existencia de notables colecciones privadas de arte que permanecieron intactas gracias a que los franceses no llegaron a tomar la ciudad ${ }^{5}$.

En Estados Unidos el fenómeno del coleccionismo fue más tardío situándose en torno a los años de la Guerra Civil, cuando los ingresos obtenidos gracias al crecimiento de empresas industriales y comerciales en esos años fomentaron la construcción de grandes mansiones decoradas con galerías de pinturas. Los grandes coleccionistas pertenecieron a las generaciones de $1850 \mathrm{y}$ $1860^{6}$. Por el contrario, resulta menos conocido el interés a partir de los años finales del siglo XVIII por la adquisición y reunión de obras de arte sobre todo europeas.

Tras la independencia, Estados Unidos se aplicó en la recuperación económica a través de la expansión comercial y para ello su posición como neutral en todos los conflictos europeos de finales del siglo XVIII y principios del XIX fue clave, ya que favoreció no solo su visibilidad desde el punto de vista diplomático, sino el crecimiento de su comercio exterior; todo lo cual tuvo su reflejo en la formación de significativas fortunas entre los comerciantes de las ciudades portuarias más importantes como Filadelfia, Boston o Nueva
York. Mercaderes y armadores derivaron parte de sus beneficios hacia actividades culturales, participando en la reconstrucción de las ciudades, aportando dinero para la construcción de templos', formando parte de asociaciones culturales ${ }^{8}$, piadosas o políticas?. Es en esos años cuando surgen instituciones como la Academia de Bellas Artes de Filadelfia en 1805, o el Athenaeum de Boston en 1807, que se interesaron muy pronto por el coleccionismo de obras de arte ${ }^{10}$. De estos años iniciales del siglo XIX apenas se conocen colecciones artísticas pertenecientes a particulares. Se sabe que Thomas Jefferson tenía una hermosa colección; aunque quizás las colecciones más citadas en estas primeras décadas del siglo XIX fueron las de José Bonaparte, exiliado en New Jersey hasta 1841 y la Richard W. Meade, tanto por el número de obras como por el hecho de reunir sobre todo pintura europea. Fue sin duda, esta última la que probablemente llegó a tener mayor visibilidad en el mercado artístico estadounidense al exponerse para su venta en diversas ocasiones.

En este artículo me propongo poner en valor la colección artística que el comerciante de Filadelfia Richard W. Meade reunió en Cádiz, ciudad en la que recaló de manera accidental y donde centralizó sus negocios durante dieciséis años. Meade invertiría una parte de los beneficios obtenidos, de las importaciones de víveres a España y de las exportaciones de vino que como contrapartida envió a Estados Unidos, en reunir una interesante colección de pinturas que trasladaría a Estados Unidos en 1816.

A partir del inventario de sus bienes realizado por la Orphan's Court" de Washington y de los dos catálogos de la colección publicados en Estados Unidos para una exposición y una subasta, se analizará el interés del mercado estadounidense, en la primera mitad del siglo XIX, por la pintura europea y en particular la española.

La presencia de pintura española en las colecciones del Reino Unido está bien documentada para las primeras décadas del siglo XIX sobre todo a partir de la publicación en 1824 de las memorias de William Buchanam un marchante de arte escocés ${ }^{2}$. Incluso se conoce el impacto que la labor de distribución de este tipo de empresarios tuvo en el gusto por la pintura española entre el público británico ${ }^{13}$. Sin embargo, poco o nada se 
sabe de la presencia de pintura española en colecciones estadounidenses en esa misma época. Para la segunda mitad del siglo XIX queda acreditado el interés por lo español y especialmente por la adquisición de obras de pintores españoles, a partir de los trabajos de Kagan ${ }^{14} \mathrm{y}$ de otros investigadores, sobre todo desde la publicación de la obra de Washington Irving, pero falta información acerca de colecciones particulares en Estados Unidos para las primeras décadas del siglo XIX y sobre la existencia en ellas de obras españolas. El estudio comparativo de los dos catálogos de la colección de Richard W. Meade publicados en 1831 y 1853 , y de otras exposiciones previas de algunas obras pertenecientes a dicha colección, permitirá conocer no solo el contenido de la colección, sino aportar información sobre la llegada a Estados Unidos de la pintura barroca española, junto a la italiana y flamenca.

\section{Noticias sobre la colección de pinturas de Richard W. Meade en Estados Unidos}

Según el inventario realizado en 1828 por la Orphan's Court de Washington Richard Meade en el momento de su fallecimiento disponía de un patrimonio valorado en más de ocho mil dólares $^{15}$. Había regresado a Estados Unidos en 1820 después de haber pasado 16 años en España, entre Cádiz y Madrid. En 1804 se estableció con su familia en Cádiz abriendo entonces la única casa comercial de un ciudadano estadounidense en la ciudad. Meade aunque recién llegado, no era un neófito en el mundo de los negocios. Su padre regentaba en Filadelfia una importante firma comercial que operaba con Europa y el Caribe. Tras colaborar durante los años de aprendizaje en la empresa de la familia constituyó su propia firma e hizo lucrativos negocios en el Caribe y América del sur. Fueron precisamente estos negocios los que le condujeron a España, en busca de una indemnización después del embargo que él y otros comerciantes estadounidenses habían sufrido en Buenos Aires, en 1802, por parte del gobierno español, y que ascendía a un millón de dólares ${ }^{16}$.

En Cádiz, Meade se convertirá en el intermediario de importantes casas comerciales estadounidenses asumiendo la mayoría de las consignaciones de mercancías que llegaban procedentes de Estados Unidos. La correspondencia que man- tenía con algunos colegas de Filadelfia confirma su interés por la adquisición de mobiliario, libros y arte decorativo durante su estancia en Cádiz. En 1810, cuando los franceses sitiaron la ciudad, Meade embarcaría, junto a su familia, todos los enseres que había logrado reunir hasta entonces y entre los que se contaban muchos muebles, instrumentos musicales y una primera biblioteca de libros en español y francés ${ }^{17}$.

Durante los años de la invasión francesa de la Península los negocios en Cádiz fueron propicios para el comercio estadounidense, que intensificó sus exportaciones de víveres para proveer a las tropas y a la población que allí se refugiaba $y$, por ende, fueron años también beneficiosos para aquellos comerciantes involucrados en estas actividades. Probablemente en un alarde de entusiasmo por la buena racha e imbuido por cierto espíritu revolucionario y republicano, Meade prestó, entre 1810 y 1812, importantes cantidades de dinero al gobierno provisional: a la Junta Central primero y después a la Regencia. Estos préstamos serían, a la postre, la causa de los problemas financieros que arrastraría hasta su muerte. Su mala situación financiera ocasionó su encarcelamiento en 1816, durante dos años, a causa de ciertas operaciones financieras poco transparentes. $Y$ es en ese año cuando vuelve a repatriar a su familia (que había regresado en 1812) y con ella, nuevamente enseres de su casa, concretamente, muebles y cajas con pinturas.

Durante los dieciséis años que permaneció en Cádiz, Meade había sido capaz de integrarse en el entramado comercial gaditano, haciéndose imprescindible para los comerciantes locales y para los estadounidenses, convirtiéndose prácticamente en el único consignatario de las mercancías procedentes de Norteamérica. Era también correspondiente para algunas firmas británicas y desde su puesto de agente naval (naval agent) negociaba con las autoridades españolas los embargos de barcos y mercancías estadounidenses, la extensión de las cuarentenas y la reclamación ante los tribunales pertinentes de los apresamientos de barcos por corsarios españoles y franceses. Su personalidad impetuosa y arrogante le acarreó amistades importantes y enemistades furibundas. Hombre hábil en los negocios y resuelto en todos los ámbitos, a juzgar por los testimonios que ha 
dejado, fue metódico también a la hora de adquirir todo tipo de bienes: muebles, libros, pinturas, vino y ovejas merinas. Y cuando lo hizo lo llevó a cabo con la idea de regresar a Estados Unidos llevando todo su patrimonio consigo. En 1810 la guerra le permitió llevar a cabo la primera repatriación (muebles y libros) ${ }^{18}$, las ovejas fue enviándolas poco a poco hasta reunir un rebaño de 680 cabezas y probablemente sucedió lo mismo con las pinturas y los demás libros, que serían trasladadas seguramente casi en su totalidad en $1816^{19}$.

La primera noticia que se tiene sobre la existencia de la colección de pinturas de Richard Meade procede del inventario de su patrimonio que se hizo en 1828 con motivo de su muerte. En este documento se recogen numerosas partidas de muebles, menaje de casa, instrumentos musicales, carruajes, vino, ovejas, animales de tiro, libros, pinturas y esculturas. Concretamente se señala la existencia de 136 "oil paintings of different kinds and sizes", 7 "family portraits", 10 "family miniatures", "one marble bust of Washington", "one marble bust of count d'Estagne", todo ello valorado en 1.205 dólares, de los cuales 1.000 dólares correspondían a las 136 pinturas, 35 dólares a los siete retratos familiares entre los que probablemente estaba el del propio Meade realizado por Vicente López en 1815 y que se halla en el Meadows Museum, 20 dólares a las diez miniaturas, 100 al busto de Washington y 50 dólares al busto del conde d'Estgne; y sin que en el inventario se ofrezca ninguna información adicional sobre el origen de las pinturas, contenido o autoría.

La siguiente referencia sobre la colección procede de una noticia en el New York Mirror ${ }^{20}$ donde se informa sobre la celebración de una exposición exclusiva de las pinturas en la National Academy of Design, de Nueva York. En la Frick Art Reference Library se conserva un ejemplar del catálogo de la colección donde se refieren un total de 87 obras numeradas, con sus dimensiones, la atribución de autoría en aquellos casos en que era conocida y también a veces una descripción de la escena que se representa ${ }^{21}$.

La exposición celebrada en Nueva York tenía como finalidad la venta de una parte importante de las obras de la colección de Richard W. Meade, y aunque no se declara ni en el artículo del New York Mirror, ni en el propio catálogo, el motivo de dicha venta, parece que esta tenía que ver con la mala situación económica por la que atravesaba la familia Meade después de la muerte de Richard Meade, en agosto de 1828. No se conocen con exactitud la naturaleza de los problemas financieros, aunque es probable que pudieran derivarse, en parte, de la negativa por parte del gobierno estadounidense a pagar a Richard Meade las deudas que había contraído con el gobierno español y que, en el tratado de 1821 por el que se vendía la Florida a Estados Unidos, se comprometía a amortizar tanto a Meade como a otros ciudadanos estadounidenses que prestaron importantes cantidades de dinero al gobierno español durante los años de la invasión francesa de la Península.

La venta de las pinturas en Nueva York no parece que fuera un éxito ya que veinte años después con motivo de la muerte de su esposa Margaret Meade, en 1853, la familia sacó a subasta un número mayor de obras, concretamente 103, que fueron expuestas en la Academy of Fine Arts de Filadelfia. El catálogo de la subasta demuestra que volvieron a exhibirse buena parte de las que se colgaron en la exposición de Nueva York de $1831^{22}$.

Con anterioridad a estas dos apariciones de buena parte de la colección ante el público estadounidense de Nueva York y Filadelfia, se habían presentado algunas obras aisladas en al menos dos exposiciones en el Athenaeum Gallery de Boston. La primera en mayo de 1828 cuando distintas personalidades de Boston y otras ciudades cercanas prestaron doscientas setenta y tres pinturas para la muestra organizada por el Athenaeum con obras no solo de Boston sino de coleccionistas de otras ciudades ${ }^{23}$. Richard Meade proporcionó para la exposición uno de sus cuadros que sería incluido entre el grupo de los old masters ${ }^{24}$. La mayor parte de las obras expuestas en esta exposición pertenecían a pintores británicos o estadounidenses y sólo una de las pinturas se atribuía a un artista español: A Magdalen penitent del Spagnoletto, perteneciente a la colección de Thomas Jefferson ${ }^{25}$.

Dos años después, en 1830 el Athenaeum volvió a organizar una exhibición ${ }^{26}$ a la que la viuda de Meade, Margaret Meade, cedió también al- 
gunas obras de su colección, para ser vendidas. El grupo lo componían las nueve pinturas que figuran a continuación.

Pinturas expuestas en el Boston Athenaeum en 1830 propiedad de Mrs. Meade.

\begin{tabular}{|c|l|l|}
\hline $\begin{array}{c}|c| \\
\frac{1}{2}\end{array}$ & \multicolumn{1}{|c|}{ Título } & \multicolumn{1}{c|}{$\begin{array}{c}\text { Autor (según } \\
\text { catálogo) }\end{array}$} \\
\hline 11 & $\begin{array}{l}\text { Vision of St. } \\
\text { Anthony }\end{array}$ & Lucas Jordán \\
\hline 15 & $\begin{array}{l}\text { Landscape with } \\
\text { cattle }\end{array}$ & Salvator Rosa \\
\hline 19 & $\begin{array}{l}\text { Martyrdom of St. } \\
\text { Lawrence }\end{array}$ & Tiziano \\
\hline 26 & $\begin{array}{l}\text { Landscape with } \\
\text { cattle }\end{array}$ & Salvator Rosa \\
\hline 30 & $\begin{array}{l}\text { St. Francis doing } \\
\text { Penance }\end{array}$ & $\begin{array}{l}\text { Desconocido. } \\
\text { Atribuido a } \\
\text { Tintoretto }\end{array}$ \\
\hline 67 & St. Peter weeping & Llorente \\
\hline 68 & $\begin{array}{l}\text { St. Anthony with } \\
\text { the Infant }\end{array}$ & Desconocido \\
\hline 75 & $\begin{array}{l}\text { Jacob wrestling } \\
\text { with the Angel }\end{array}$ & Domenichino \\
\hline 218 & $\begin{array}{l}\text { Joseph and his } \\
\text { Brethren }\end{array}$ & Desconocido \\
\hline
\end{tabular}

Fuente: The North American Review, vol. 31, 69 (Oct., 1830) pp. 309-337

Se trata de un grupo relevante, aunque poco numeroso, de pintura barroca italiana, representados por Lucas Jordán, Domenichino, Salvator Rosa y Tiziano. Pero los elevados precios de estas obras dificultaron tanto su venta al público como que fueran adquiridos por el propio Athenaeum ${ }^{27}$.

En la exposición se colgaron además dos cuadros de Murillo que no estaban a la venta. El número 70, The pet kitten que pertenecía a Mr. MacMurtrie y el número 114, The meeting of Rebecca and Abraham's servant, que era propiedad del mismo Athenaeum.

Los tres documentos aludidos, a saber: el inventario de su patrimonio realizado en 1828, el catálogo de la exposición de Nueva York de 1831 y el catálogo de la subasta de 1853 permiten una aproximación a la colección de Richard W. Meade tanto desde el punto de vista numérico como de su contenido y calidad. De hecho, de las 155 obras que figuran en el inventario, los dos catálogos ofrecen algún tipo de información sobre 129 de ellas (127 pinturas y dos bustos).

A falta de documentos privados los catálogos localizados brindan, como se ha dicho, un valioso conocimiento de la colección de pinturas de Richard W. Meade. Sin embargo, hay que advertir de posibles problemas derivados del manejo de este tipo de fuentes. En primer lugar, en los catálogos una misma obra puede estar referenciada de distinta forma. No suele ser lo habitual en estos primeros años, ya que cuando se trata de catálogos de la misma colección solían copiarse los títulos para evitar confusiones. Pero cuando se cruzan fuentes privadas y los catálogos si pueden aparecer discordancias en la identificación de las obras. Por ejemplo, según el crítico de la The North American Review (Revista publicada por el Athenaeum), en 1829 el Athenaeum compró a William Foster la obra Jacob at the well Drinking from the cruce of Rachael atribuyéndose su autoría a Tiziano, y que resultó ser la misma que un año después se expuso con otro título: The meeting of Rebecca and Abraham's servant, y atribuida a Murillo. Otro caso similar se dio con una obra atribuida a Velázquez en el catálogo de la colección de R. Meade. Thomas Jefferson Bryan adquirió en la subasta de la Meade's Gallery en Filadelfia, en 1853 el Portrait of the Lady who was betrothed to the son of Philip $1 / 28$ of Spain y en 1867 donó la pintura titulada Portrait of Infanta Margarita, a la New-York Historical Society donde actualmente se conserva, pero ahora atribuido a Juan Bautista Martínez del Mazo. A pesar de los títulos diferentes se trataba de la misma pintura.

Otro de los problemas imputables a los catálogos publicados en las primeras décadas del siglo XIX en Estados Unidos, es el relacionado con las atribuciones de autoría de las obras. No había expertos que confirmaran la veracidad de la autoría que los propietarios declaraban. De hecho en ninguno de los catálogos consultados aparece referencia alguna a la autentificación de las obras por expertos. Al contrario, se reitera en ellos que "the committee have not undertaken 
in any instance to designate the names of the authors of the Works ascribed to the Old Masters, but have invariable adopted the names indicated by respectives owners o que every painting is sincerely believed to be an undoubted original by the artista named" ${ }^{29}$. En muchos casos las únicas referencias que se tienen sobre los cuadros o sus autores son las memorias publicadas por algunos marchantes británicos y donde aparecen listas de obras, o bien se recurre a obras generales en busca de algún tipo de información ${ }^{30}$.

La falta de expertos lleva en ocasiones a errores que terminan reconociendo los propios expositores. La pintura The meeting of Rebecca and Abraham's servant, anteriormente mencionada, fue catalogada como obra de Tiziano en 1829 hasta que en 1830 el crítico de la The North American Review la atribuyó a Murillo.

En los catálogos de la colección de Richard W. Meade también se dan algunos de estos errores. Por ejemplo, en el catálogo de la exposición de 1831 aparece una pintura pequeña en cobre titulada St. Anthony and the Infant atribuida a Murillo mientras que en el catálogo de 1853 aparece St. Anthony, with Infant in his arms de Luca Giordano también en cobre y del mismo tamaño. Inicialmente parecen ser la misma pintura aunque es arriesgado afirmarlo sin contar con las descripciones detalladas de ambos cuadros. También, en el catálogo de 1853 figuraban dos retratos atribuidos a Velázquez que no habían sido expuestos previamente en 1831 y que actualmente se atribuyen a Juan Bautista Martínez del Mazo ${ }^{31}$.

\section{3. ¿Cómo pudo reunir Richard W. Meade su colección?}

Conocer la procedencia de cada una de las obras que forman la colección de Meade es una tarea poco menos que imposible con las fuentes disponibles hasta ahora. Tal vez la única certeza sea que el grueso de la colección pudo ser reunida durante su estancia en España, aunque el título del catálogo de 1831 siembra algunas dudas al aseverar que las obras "are collected in Europe" Pero es en el mismo catálogo también donde se señala expresamente que algunas de las obras fueron adquiridas en España ${ }^{33}$, entrando incluso en detalles de cómo se compraron. Así, en la des- cripción de la pintura El martirio de San Lorenzo de Tiziano se explica que la obra se encontraba en Madrid y fue "tomada por el ejército francés y comprada por el Sr. Meade, en la vecindad de Cádiz" ${ }^{34}$. Lo que permite pensar que la guerra pudo ser una las fuentes de la colección aunque, probablemente, no la única.

Cádiz al igual que Sevilla era un mercado propicio para la adquisición de obras de arte ${ }^{35}$. Antonio Ponz menciona en el diario de su viaje como cambiaban de mano parte de las colecciones y cómo estas transferencias estaban directamente relacionadas con el fallecimiento de los propietarios $^{36} \mathrm{o}$ con eventuales problemas financieros derivados de las incertidumbres provocadas por los recurrentes conflictos bélicos ${ }^{37}$

Meade pudo adquirir algunas obras de su colección a través de una de las dos vías. Por ejemplo, la coincidencia en el tiempo de la venta de parte de la colección artística de Sebastián Martínez ${ }^{38}$, uno de los más importantes coleccionistas de arte de Cádiz y la estancia de Meade en la ciudad, puede llevarnos a admitir, de manera hipotética, que este último pudo adquirir algunas de las pinturas del riojano. La semejanza en los títulos de algunas obras, registradas en el inventario que se hizo ante notario, de la colección artística de Sebastián Martínez y los atribuidos a las que aparecen en los catálogos de la colección de Meade, podría hacer pensar en algún tipo de transferencia de estas obras entre ambos comerciantes. Sin embargo, a pesar de encontrar similitudes en los títulos, la relación hecha por el notario es tan imprecisa que resulta aventurado y especulativo aseverar que se trate de las mismas obras. Por ejemplo: la pintura descrita en el inventario de los bienes de Sebastián Martínez como "un hombre que enciende la pipa con un tizón" y que fue tasado en 375 reales $^{39}$, puede corresponderse con cualquiera de los números 70 y 71 del catálogo de 1831 de la colección de Meade que aparecen con el título, Dutchmen Smoking atribuidos a la escuela flamenca y valorados cada uno en 30 \$; otro cuadro "que representa una Magdalena" según reza el inventario de Sebastián Martínez y valorado en 750 reales ${ }^{40}$, podría ser "La Magdalena" atribuida a van Dyck del catálogo de $1831^{41}$ y cuyo precio era de $1.000 \$$. Y finalmente, es posible buscar similitudes también 
entre el cuadro que "representa gallos y gallinas" calificado como "excelente" por el tasador del inventario de Martínez y que lo valoró en la nada despreciable cantidad de 1.500 reales $^{42}$, y una de las dos pinturas que aparecen en el primer catálogo de la colección de Meade, el de 1831, con el título de Domestic Fow/44, valorados en $80 \$$ cada uno y sin autoría, pero que en 1853 se atribuyen a Carrenno (sic) ${ }^{44}$. Naturalmente la hipótesis de una posible identificación o correspondencia entre estas pinturas tiene mucho de especulación, puesto que no hay ninguna prueba documental que avale una compraventa de estas obras, salvo el comentario de Nicolás de la Cruz, conde de Maule que asegura en sus memorias que una de las hijas y herederas de Sebastián Martínez vendió las obras de arte a los ingleses ${ }^{45}$.

Según uno de los biógrafos del general George Gordon Meade, hijo del comerciante Richard Meade, parece que su padre pudo obtener algunas importantes piezas de su colección como pago de deudas contraídas por otros comerciantes con él. Esta hipótesis no ha sido corroborada por carecer de los libros de contabilidad o algún documento del propio Meade que lo acredite, aunque podría ser una hipótesis posible ya que la estancia de Meade en Cádiz coincidió con una coyuntura comercial difícil para muchos comerciantes, como demuestran el número creciente de quiebras de importantes casas comerciales que se venían sucediendo desde los años ochenta del siglo XVIII en Cádiz y que se intensificaron a partir de 1802 y hasta $1824^{46}$.

Igual que en otros tipos de comercio, en el mercado del arte existía la figura del intermediario, marchante o comerciante especializado en la compraventa de obras de arte y de los que se conocen algunos ejemplos famosos en estos años, como James Wisseman con buenos contactos en Sevilla ${ }^{47}$, William Buchanam que a través de agentes en Italia o España compró obras de arte para renombrados coleccionistas británicos o David Wilkie o Wilkes pintor, crítico y marchante de arte británico ${ }^{48}$. Meade como comerciante y coleccionista de arte debió también recurrir a intermediarios para aumentar su colección. Esto explicaría el hecho de que entre las pinturas de Meade se halle el cuadro que representa a Santo Tomas de Villanueva distribuyendo limosna a los pobres. Esta pintura aparece identificada como "Copy from Murillo, by one of this pupils, and said to be equal to the original. Murillo considered this the finest of his painting." El original se hallaba en Génova en 1804 a donde fue trasladado por Giovanni Bielato, un comerciante genovés que lo compró en Cádiz junto a otras pinturas de Murillo y lo donó a la iglesia de los Capuchinos en Génova. Según José Luis Colomer, en 1804 el comerciante William Buchanam y su agente en Génova James Irivine, compraron las obras y entre ellas el Santo Tomas de Villanueva que en 1848 fue a parar a la colección privada de Richard Seymour-Conway, IV marqués de Hertford $^{49}$ Es posible que en algún momento, entre su traslado de Génova y su venta en Inglaterra, Meade encargara una copia.

Otro posible ejemplo de la utilización de agentes puede ilustrarse con la adquisición del busto de George Washington que aparece en la colección de Meade. El busto fue comprado en Filadelfia por el embajador español en Estados Unidos José Jáudenes ${ }^{50}$. Más tarde, en una fecha posterior a la muerte de Jáudenes (octubre de 1812) Meade se lo compró a su viuda, que residía en Mallorca, por 2.000 dólares. Finalmente en 1853 Governeur Kemble se lo compraría a la esposa de Robert Meade, uno de los hijos de Richard Meade, y actualmente se conserva en el Metropolitan Museum de Nueva York.

Es probable que la condición de comerciante de un país neutral y colaborador con el gobierno provisional, pudo permitirle a Meade acceder a las ventas de bienes de algunos potentados que no apoyaron al gobierno de la Junta Central y a la Regencia como el duque de Alba, el duque de Híjar o el príncipe de la Paz (Godoy) que poseían importantes colecciones artísticas.

No sabemos nada sobre el coste total de la inversión que hizo Meade en las pinturas. Pero, aunque carecemos de información cuantitativa procedente de sus libros contables, podemos, sin embargo, acercarnos a la valoración que el propio Meade y su familia hicieron de estas adquisiciones. La correspondencia de su hija desvela que la formación de esta colección fue pensada y meditada como complemento a otras inversiones, y que fue considerada por Meade como un activo refugio a medio y largo plazo en el caso de que la 
familia tuviera dificultades económicas, llegando a lamentarse su hija de la tasación tan pobre, que en el inventario de los bienes de Meade se hizo, valorándolas tan solo en 1.000 dólares cuando se decía que su valor estaba en torno a los 50.000 dólares. ${ }^{51}$.

Al margen del valor económico, en la documentación existente no se menciona nunca la motivación que movió a Meade a la hora de elegir. Naturalmente, cuando lo que se pretendía era saldar una deuda, no cabía ningún tipo de selección; pero suponemos que en otras ocasiones pudo pesar el valor emocional, ya que Meade era católico, lo que explicaría que buena parte de las pinturas fueran de temas religiosos.

\section{El mercado estadounidense y la pintura española}

La publicación en Inglaterra de memorias como las de Buchanam o Wilkie ayudó probablemente a comprender y valorar la pintura que llegaba de Europa a Estados Unidos. Los críticos de la The North American Review de hecho citan la autoridad de estos comerciantes de obras de arte, admitiendo, al mismo tiempo, el poco conocimiento que se tenía en Estados Unidos sobre la pintura española. De hecho eran escasas las galerías de arte que exponían pintura europea y menos aun las que colgaban obras de los denominados old masters ${ }^{52}$.

En las primeras décadas del siglo XIX la pintura española era poco reconocida en Estados Unidos y no era habitual encontrarla en las colecciones privadas o en exposiciones de instituciones como el Atenaeum de Boston. La influencia de los gustos y de los críticos de arte británicos podía estar detrás de esta realidad ya que pintores españoles como Murillo o Velázquez, no habían sido apreciados en Inglaterra hasta esas fechas ${ }^{53}$. El desconocimiento de estos artistas se debía a que España quedaba fuera de la ruta regular de los viajes que por negocios o por placer, comerciantes y nobles realizaban por Europa, de modo que estas obras de arte habían sido secuestradas, por así decirlo, de la vista del público. De ahí que los nombres de Murillo y Velázquez, fueran mucho menos familiares para el público europeo que muchos artistas italianos y flamencos de menor mérito. Sin embargo, algunas de las obras de estos artistas españoles llegaron a Paris tras la invasión francesa de la península, al tiempo que ciertos grabados de sus pinturas publicados entonces se difundían por Europa.

A Estados Unidos empezaron a llegar algunas pinturas de Murillo, tanto originales como copias desde finales del siglo XVIII, aunque no es hasta el siglo XIX cuando comienzan a ser apreciadas y aparecen con cierta asiduidad en algunas colecciones. En 1830 parece que había alguna en la Academy of the Arts en Nueva York, pero la mejor pintura de Murillo en opinión de los organizadores de las exposiciones del Athenaeum de Boston, era sin duda The Roman Charity que se guardaba en la Academy of the Arts de Filadelfia y que fue adquirida por Mr. Rich en España cuando ejercía como cónsul en Valencia. Esta pintura sufrió algunos daños mientras estuvo expuesta en la casa del cónsul en España y su restauración corrió a cargo del pintor valenciano Vicente López, aunque a juicio de su propietario no fue muy afortunada. El propio Athenaeum era propietario de un Murillo que se expuso en 1830 en su cuarta exposición, se trataba de The meeting of Rebecca and Abraham's servant ${ }^{54}$ que fue adquirido a William Foster en 1829 quien lo había comprado en España treinta años antes. Parece, por tanto, que la fuente de todas estas pinturas eran compras hechas directamente en España. Como lo eran también los Murillos que en 1831, se expusieron en Nueva York pertenecientes a la colección de Richard W. Meade: The three wise men, with offerings to the Infant, St. Anthony and the Infant y The visitation of Joseph and Mary to Elizabeth, además de dos copias, St. Thomas of Villanueva, giving alms, realizada por un pupyl de Murillo y The visión of St. Francis receiving the Saviour from the cross; a los que habría que añadir otra obra atribuida a Murillo y que se subastó en 1853 en Filadelfia: The martyrdom of Ermiterio and Celedonio (en cobre).

En Estados Unidos circulaban igualmente copias de Murillo realizadas en España, en Francia y en Inglaterra. James Hamilton en 1795 tenía una realizada por Benjamin West, se trataba de la pintura titulada St. Ignatius captured by a Spanish Vessel. En 1835 se localiza una copia de la The Holy Family de Murillo que se expuso en Boston 
y que fue comprada en París por Francis Calley Gray ${ }^{55}$.

Desde la muerte de Richard Meade, la familia perseveró durante más de veinte años en la venta de la colección. Resulta sorprendente la impermeabilidad del mercado estadounidense a la adquisición de pinturas de autores tan relevantes como: Velázquez, van Dyck, Rubens, Lucas Jordán, Murillo, Tintoretto, Carreño, Sánchez Cotán, Guido Abattini, Bassano, Mario Nuzzi, Tiziano, Ribera, Alonso Cano, Caravaggio, Goya, El Greco, Gilbert Stuart, Rafael Mengs, Rembrandt o Veronés. De las 129 pinturas descritas entre los dos catálogos, 65 se atribuyen a alguno de estos autores sin ningún género de duda, otros 7 cuadros se asignan a escuelas pictóricas concretas, como la escuela italiana o la escuela de Rubens o la escuela de Murillo, en el caso de dos cuadros los catálogos difieren en la originalidad de las obras (Murillo o copia de Murillo) y las 55 pinturas restantes no se atribuyen a ningún autor o escuela pictórica.

Predominan las obras de temas profanos, 63 son paisajes y naturalezas muertas, entre los que hay algunas marinas y escenas de género, 45 son pinturas religiosas, seis son obras que representan temas mitológicos y hay diez retratos de distintos personajes (Washington, un juez, un colegial, un anciano, el general Ballesteros.... $)^{56}$.

Como ya hemos dicho, el cotejo de los catálogos de la exposición de 1831 en Nueva York y de la subasta de 1853 en Filadelfia refleja que sólo un pequeño número de pinturas se vendieron en el primer intento, concurriendo en ellas las circunstancias de precios moderados y pequeño formato. Es posible, entonces, que tanto el precio elevado como el gran tamaño de algunas de las obras expuestas explicasen la falta de interés por esta temprana oferta de pintura barroca europea. Al mismo tiempo, los posibles compradores formaban parte de la burguesía urbana de ciudades como Filadelfia, Boston, Nueva York, Baltimore, cuyas residencias no eran grandes palacios, por lo que las pinturas de gran tamaño tenían difícil acomodo en ellas. Por otro lado, la temática religiosa de muchas de estas obras tampoco era un aliciente para una buena parte de los compradores que eran protestantes, por lo que algunas pinturas no encajaban con la mentalidad iconoclasta de los cuáqueros de Filadelfia o los presbiterianos de Boston o Nueva York. Entre las pinturas más grandes y más caras que se expusieron y que no lograron venderse estaban The Calling of St. Matthew de Lucas Jordán cuyo precio se estipuló en 7.000 dólares y cuyas medidas eran 117 pulgadas de largo por 93 de ancho ${ }^{57}$ y The Martyrdom of St. Lawrence de Tiziano valorado en 5.000 dólares y con 91 pulgadas de largo por 77 de ancho ${ }^{58}$.

Las obras que no se vendieron fueron distribuidas entre los herederos de Richard W. Meade que por separado fueron vendiendo algunas de las obras, como el mencionado busto de Washington o el cuadro The Calling of St. Matthew, vendido 1860 por Martha Meade a la Universidad de Georgetown.

Los retratos familiares no salieron a la venta en ninguna de las exposiciones. Sabemos de la existencia de un retrato de Margaret Coates Meade, que parece que se quemó y otro de la familia, ambos realizados por Gilbert Stuart. Meade también se hizo retratar en España por el pintor de la corte en aquellos años, Vicente López que lo pintó junto a su escritorio apoyándose en las ordenanzas del Consulado de Bilbao y en un Tratado sobre comercio y con varios volúmenes de Historia de España e Historia de América en el suelo pertenecientes a su biblioteca.

La fiscalidad no fue nunca un impedimento para la importación de obras de arte europeas a Estados Unidos, de hecho parece que hasta 1861 , se pudo importar arte sin tener que pagar aranceles específicos ${ }^{59}$. No obstante, según los documentos de la Custom House se fijaron ciertas cargas de entrada para las pinturas, esculturas, libros y muebles. En el caso de las pinturas y otros enseres, al menos se aplicaba un 15\% sobre el valor estimado que declaraba el propietario o el consignatario en la aduana. El escaso aprecio que se adjudicaba por parte de los interesados a este tipo de objetos, conllevaba el pago de cantidades poco importantes a la entrada en los puertos estadounidenses. Por ejemplo una de las cajas de pinturas propiedad de Richard Meade que llegó a Filadelfia en el navío Strong, consignada a su esposa, fue valorada en diez dólares, lo que significaba el pago de un arancel de entrada de 1,5 dólares. En la Custom House de Filadelfia no 
El mercado de pintura Española en Estados Unidos en las primeras décadas del siglo XIX

๗ Se abrió la caja ni se consideraron los tamaños de

los objetos o el valor de compra.

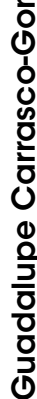

que reunió una colección artística en Europa que luego trasladó, exhibió en repetidas ocasiones e intento vender en Estados Unidos. Todo lo cual demostraría que el estudio de los patrimonios de comerciantes, agentes y diplomáticos estadounidenses destinados en Europa puede contribuir a arrojar luz sobre la llegada y el conocimiento de la pintura europea en Estados Unidos. 


\section{NOTAS}

1 Sobre el coleccionismo en Sevilla, véase Antigüedad del CASTILLO OLIVARES, M. Dolores and ALZAGA RUIZ, Amaya (eds.): Coleccionismo, expolio, museos y mercado artístico en España en los siglos XVIII y XIX. Editorial Universitaria Manuel Areces. Madrid. 2011. Para el siglo XVI se puede consultar URQUIZAR HERRERA, Antonio: Coleccionismo y nobleza. Signos de distinción social en la Andalucía del Renacimiento. Marcial Pons Historia. Madrid, 2007.

2 PONZ, Antonio: Viaje de España. vol. XVIII. Madrid. 1794, p. 25

${ }^{3}$ Véase RAVINA MARTíN, Manuel: "El mundo del libro en el Cádiz de la Ilustración", Cuadernos de llustración y Romanticismo, n 9, 2001, pp. 89-102.

${ }^{4}$ PONZ, Antonio: Viaje, p.26

${ }^{5} \mathrm{NOAH}$, Mordecai: Travels in England, France, Spain and Barbary States in the year 1813-14 and 15. Publised by Kirk and Mercein. New York. 1819. p. 140.

${ }^{6}$ KAGAN, Richard L.: "The Spanish Craze in the United States: Cultural Entitlement and the Appropriation of Spain's Cultural Patrimony, 18901930". En: Revista Complutense de Historia. $n^{\circ} 36$, 2010. pp. 37-58. Del mismo autor y recientemente publicado, The Spanish Craze: America's Fascination with the Hispanic World, 17791939. University of Nebraska Press. Lincoln. 2019.

7 George Meade, padre de Richard Worsan Meade participó activamente en la construcción de Saint Mary's Church

8 La American Philosophical Society fundada por Benjamin Franklin en Filadelfia en 1743 fue especialmente activa durante los años finales del siglo XVIII cuando era presidida por Thomas Jefferson. John Vaughan, mercader de vinos y bibliotecario de la American Philosophical Society estaba interesado por los fósiles, particularmente de mamuts, por eso en 1804 escribe a Richard W. Meade a Cádiz encargándole cualquier libro que sobre ese tema se publicara en España.

${ }^{9}$ George Meade y Tomas Fitzsimons estaban entre los fundadores de la Friendly sons of Saint Patrick una organización social que existió en Filadel- fia entre 1771 y 1798 constituida por nativos irlandeses y sus hijos.

${ }^{10}$ Entre el final de la Guerra Revolucionaria y la fundación de la Academia de Pennsylvania en 1805, se hicieron intentos de establecer sociedades artísticas en Filadelfia y en la ciudad de Nueva York. El Museo de Peale, fundado en 1786 por Charles Wilson Peale en Filadelfia, fue uno de los primeros.

${ }^{11}$ Historical Society of Pennsylvania (HSP), Cadwalader Papers, Legal Papers, Box 13.

${ }^{12}$ HARRIS, E: Estudios completos sobre Velázquez. Complete Studies on Velázquez. CEEH. Madrid, 2006. p. 196.

${ }^{13}$ GLENDINNING, N. and MACARTNEY, H. (eds.): Spanish Art in Britain and Ireland, 1750-1820. Woodbridge: Tamesis, London, 2010.

${ }^{14}$ KAGAN, Richard L.: "The Spanish Craze".

${ }^{15}$ HSP, Cadwalader Papers, Legal Papers, Box 13

${ }^{16}$ CARRASCO-GONZÁLEZ, Guadalupe: "La presencia de comerciantes estadounidenses en España a finales del Antiguo Régimen: La actividad mercantil y los negocios de Richard Worsan Meade (1804-1818)". Chronica Nova, $n^{\circ} 44,2018$, pp. 215-242.

${ }^{17}$ Ibídem, pp.238-239

${ }^{18}$ Los muebles y los libros aparecen consignados a Margaret Meade, su esposa, que al mismo tiempo figura como pasajera en el barco llamado Romp. National Archives and Record Administration (NARA), RG 36 Records of The Bureau of Customs. Inward Foreign Manifests, Aug1, 1810-Aug 31, 1810. Box 119 NC-154 Entry 1059

${ }^{19}$ En el brig Strong Meade cargó varias cajas de pinturas, quedando registrada en la Aduana de Filadelfia su entrada en octubre de 1816. NARA, RG 36 Records of The Bureau of Customs. Inward Foreign Manifests, Oct. 1816. Box 130 NC-154 Entry 1059.

20 "Exhibition of Paintings, Collected in Spain by the Late Richard W. Meade, Esq.", New York Mirror, September 17, 1831, pp. 86-87.

${ }^{21}$ Frick Art Reference Library, NY, The Frick Collection, ND454. M33, 1831
${ }^{22}$ Library Company of Philadelphia, SM \#AM 1853, Mea.

${ }^{23} \mathrm{~A}$ Catalogue of the 2nd exhibition in the Athenaeum Gallery: consisting specimens by American artist, and a selection from the Works of the old masters. Boston, May 1, 1828. Boston Athenaeum. Fine Arts Department. A parte de ciudadanos de Boston, también prestaron pinturas el Dr. De Wees, la Sra. Hughes y Patrick Lyon de Filadelfia, Isaac P. Hone de Nueva York, R. W. Meade de Washington, John Neal de Portland, Maine, D. Wadsworth de Hartford, Connecticut, y R. Gilmor y J. Hoffman de Baltimore.

${ }^{24}$ Ibídem, número 82 , p. 2, "An early picture the late B. West". El catalogo contenía 318 obras, con el título, el nombre del artista y el nombre de su propietario. Cinco de esas pinturas fueron catalogadas como old masters.

${ }^{25}$ Ibídem, número 283, p.8.

${ }^{26}$ The fourth exhibition in the Gallery of the Boston Athenaeum. 1830. Boston Athenaeum. Fine Arts Department. En este catálogo figuraban 224 obras, cada una de las cuales aparecía con su título, autor, en algunos casos una descripción más o menos detallada, en función de si el autor era un artista conocido o si la obra era especialmente relevante $y$, además, se incluía el nombre del propietario.

${ }^{27}$ El Boston Athenaeun justifica así no haber adquirido el Martirio de San Lorenzo de Tiziano. The North American Review vol. 31, 69(Oct., 1830) pp. 309-337.

${ }^{28}$ En el catálogo de la subasta de 1853 hay un error y debe referirse a Felipe III.

${ }^{29}$ Library Company of Philadelphia, SM \#AM 1853, Mea.

30 "Diccionario Histórico de los más ilustres profesores de las bellas artes en España". En el catálogo de 1831, se advierte en una nota final que "Desde que se imprimió la primera parte de este catálogo, hemos tenido la oportunidad de consultar el artículo "Ticiano Vecelio", en el "Diccionario Histórico de los más ilustres profesores de las bellas artes en España" y encontrar que la famosa pintura del Martirio de San Lorenzo fue enviado por Tiziano a Felipe II, y colocado sobre el gran altar de la Iglesia Vieja, en 
Madrid. Este trabajo describe la pintura con justicia, en los términos más brillantes, como una de las obras maestras del gran artista".

${ }^{31}$ Portrait of the Lady who was betrothed to the son of Philip II of Spain (The Pearls and Dress are said to be inimitable) y Portrait of Maria Theresa, daughter of Philip II actualmente se conserva en la New-York Historical Society, y Portrait of Maria Theresa, daughter of Philip /I que se conserva en el Metropolitan Museum de Nueva York y ha sido atribuido a la escuela de Velázquez.

${ }^{32}$ Catalogue of Italian, Spanish, Flemish and Dutch paintings, collected in Europe, and brought to this country by Richard W. Meade, Esq. New York. 1831.

${ }^{33}$ La llamada de San Mateo de Lucas Jordán o El martirio de San Lorenzo de Tiziano.

34 "... and many of his best pictures were pinted in Madrid, from whence this great work was removed by the French army, and purchased by $\mathrm{Mr}$. Mead, in the neighbourhood of Cadiz". Catalogue of Italian, Spanish...op. cit. p. 5.

${ }^{35}$ Existe una amplia bibliografía sobre el coleccionismo en Cádiz y Sevilla durante los siglos XVII y XVIII recogida en varios trabajos. Véase CASTILLO OLIVARES, M. Dolores and ALZAGA RUIZ, Amaya (eds.): Coleccionismo, expolio, museos y mercado artístico en España en los siglos XVIII y XIX. Editorial Universitaria Manuel Areces. Madrid. 2011.

${ }^{36}$ PONZ, Antonio: Viaje, p. 22.

${ }^{37}$ GARCÍA-BAQUERO GONZÁLEZ, Antonio: Comercio colonial y Guerras revolucionarias. Escuela de estudios Hispanoamericanos, Sevilla, 1972.

${ }^{8}$ PEMÁN MEDINA, María: "La colección artística de Don Sebastián Martínez, amigo de Goya en Cádiz" , Archivo Español del Arte, 201. 1978. p. 62.

${ }^{39}$ Archivo Histórico Provincial de Cádiz (AHPC), Protocolo 5387, f. 146.

${ }^{40}$ Ibídem, f. 155.

${ }^{41}$ Catalogue of Italian, Spanish... $\mathrm{n}^{\circ}$ 34.

${ }^{42}$ AHPC, Protocolo 5387, f. 156

${ }^{43}$ Catalogue of Italian, Spanish,..., $n^{\circ} 54$ y 55 .

${ }^{44}$ Ibídem, $n^{\circ} 58$ y 79.

${ }^{45}$ PEMAN MEDINA, Maria: "La Colección artística", p. 62.

${ }^{46}$ Sobre las quiebras de comerciantes desde la década de los ochenta del siglo XVIII y hasta 1824, véase también BERNAL, Antonio Miguel: La financiación de la Carrera de Indias (14921824), Madrid. 1992.

${ }^{47}$ FERNÁNDEZ GARCÍA, A. M.: "Pintura y comercio. Las relaciones anglo-españolas en el siglo XIX", Norba, XVIII-XIX. 1998-1999, pp. 31-241.

${ }^{48}$ Véase CUNNINGHAN, A.: The life of sir David Wilkie with his journals, Tours and critical remarks on Works of arts, and a selection of his correspondence, 3vols, London, 1843.

${ }^{49}$ BOCCARCO, P., COLOMER, J.L. Y FABIO, C. (coords.): España y Génova: obras, artistas y coleccionistas, Fundación Carolina, Centro de estudios Hispánicos e Iberoamericanos, Fernando Villaverde ediciones. Madrid. 2002, p. 237.

${ }^{50}$ José Jáudenes regresó a España en 1796.
${ }^{51}$ Carta de Margaret Meade, hija, a John Cadwalader, Washington City 8 de octubre de 1843 y del 2 de noviembre de 1843. HSP, Judge John Cadwalader Papers. Legal Papers. Box 287

${ }^{52}$ En 1828 el Columbia Centinel anunciaba la apertura de una exposición en el Boston Athenaeum con 273 pinturas de las que 85 fueron catalogadas como Old Master.

${ }^{53}$ HARRIS, E.: Estudios completos sobre Velázquez. Complete Studies on Velázquez, CEEH, Madrid, 2006.

${ }^{54} \mathrm{~A}$ Catalogue of the 2nd exhibition in the Athenaeum Gallery: consisting specimens by American artist, and a selection from the Works of the old masters, Boston, May 1, No 144. 1828.

${ }^{5}$ SWAN, M.M.: The Athenaeum Gallery 1827-1873. The Boston Athenaeum as an Early Patron of Art, Boston, 1940, p.127

${ }^{56}$ CARRASCO-GONZÁLEZ, Guadalupe: "Invertir en arte: La colección de pintura reunida por el comerciante estadounidense Richard Worsan Meade en Cádiz entre 1804 y 1820", Archivo español del Arte, $n^{\circ}$ 365. 2019. pp.65-82.

${ }^{57}$ Las medidas no coinciden en los dos catálogos. Mientras que en el de 1831 las medidas son $117 \times 93$ pulgada, en el de año 1853 las medidas son $103 \times 81$ pulgadas

${ }^{58}$ En el catálogo de 1831 las medidas eran $91 \times 77$ pulgadas y en el de 1853, 78x63 pulgadas.

${ }^{59}$ Véase BRIMO, R.: La evolution de gôut aux Etats-Unis d"apres I'histoire des collections, Paris, 1938. 


\section{REFERENCIAS}

Antigüedad del Castillo-Olivares, María Dolores, y Amaya Alzaga Ruiz, coords. 2011. Colecciones, Expolio, Museos y mercado artístico en España en los siglos XVIII y XIX. Madrid: Editorial Universitaria Ramón Areces.

Boccardo, Piero, Colomer, José Luis, and Clario Di Fabio, eds. 2002. España y Génova: obras, artistas y coleccionistas, Fundación carolina. Madrid: Centro de estudios Hispánicos e Iberoamericanos, Fernando Villaverde ediciones.

Boone, Elizabeth. 2007. Vistas de España: American Views of Art and Life in Spain, 18601914, Yale University Press.

Brimo, René.1938. La evolution de gôut aux Etats- Unis d"apres l'histoire des collections. Paris: James Fortune.

Buchanan, William. 1824. Memoirs of painting with a chronological history of the importation of pictures by the Great Masters into England since the French Revolution. London: R. Ackermann.

Carrasco-González, Guadalupe. 2018. “La presencia de comerciantes estadounidenses en España a finales del Antiguo Régimen: La actividad mercantil y los negocios de Richard Worsan Meade (1804-1818)." Chronica Nova 44: 215-242. https://doi.org/10.3989/hs.2002. v54.i109.188

Carrasco-González, Guadalupe. 2019. “Invertir en arte: La colección de pintura reunida por el comerciante estadounidense Richard Worsan Meade en Cádiz entre 1804 y 1820." Archivo español de Arte 365: 65-82. https://doi. org/10.3989/aearte.2019.06

Cunninghan, Allan. 1843. The life of sir David Wilkie with his journals, Tours and critical remarks on Works of arts, and a selection of his correspondence. 3vols. London. https://doi. org/10.1017/cbo9781139979559.016

Fernández García, Ana María.1998-1999. “Pintura y comercio. Las relaciones anglo-españolas en el siglo XIX." Norba XVIII-XIX: 31-241.
García-Baquero González, Antonio. 1972. Comercio colonial y Guerras revolucionarias. Escuela de estudios Hispanoamericanos, Sevilla. https://doi.org/10.1086/ahr/79.5.1570

Glendinning, Nigel and Macartney, Hilary, eds. 2010. Spanish Art in Britain and Ireland, 17501820. London: Woodbridge, Tamesis.

Harris, Enriqueta. 2006. Estudios completos sobre Velázquez. Complete Studies on Velázquez. Madrid: CEEH.

Kagan, Richard L. 2010. "The Spanish Craze in the United States: Cultural Entitlement and the Appropriation of Spain's Cultural Patrimony, 1890-1930." Revista Complutense de Historia 36: 37-58. https://doi.org/10.5209/ rev_rcha.2010.v36.2

Kagan, Richard L. 2019. The Spanish Craze: America's Fascination with the Hispanic World, 1779-1939. University of Nebraska Press. Lincoln. https://doi.org/10.2307/j.ctvbtzkpn

Noah, Mordecai. 1819. Travels in England, France, Spain and Barbary States in the year 181314 and 15. Publised by Kirk and Mercein. New York.

Pemán Medina, María. 1978. "La colección artística de Don Sebastián Martínez, amigo de Goya en Cádiz." Archivo Español de Arte 201: 53-62.

Ponz, Antonio. 1794. Viaje de España. Madrid.

Ravina Martín, Manuel. 2001. “El mundo del libro en el Cádiz de la llustración." Cuadernos de Ilustración y Romanticismo 9: 89-102. https:// doi.org/10.25267/cuad_ilus_romant.2001. i9.05

Roglan Mark A. 2016. Spanish Art in America. Blacker Design Publishing.

Swan, Mabel Munson. 1940. The athenaeum Gallery 1827-1873. The Boston Athenaeum as an Early Patron of Art. Boston. 